\title{
Self-activation and out-group contrast
}

\author{
Article
}

Accepted Version

Hall, N. R. and Crisp, R. J. (2010) Self-activation and outgroup contrast. The Journal of Social Psychology, 150 (5). pp. 423-427. ISSN 1940-1183 doi: https://doi.org/10.1080/00224540903365505 Available at https://centaur.reading.ac.uk/7578/

It is advisable to refer to the publisher's version if you intend to cite from the work. See Guidance on citing.

Published version at: http://www.informaworld.com/smpp/content $\sim \mathrm{db}=a \mathrm{all} \sim$ content=a926889170 frm=titlelink To link to this article DOI: http://dx.doi.org/10.1080/00224540903365505

Publisher: Taylor and Francis

All outputs in CentAUR are protected by Intellectual Property Rights law, including copyright law. Copyright and IPR is retained by the creators or other copyright holders. Terms and conditions for use of this material are defined in the End User Agreement.

\section{$\underline{\text { www.reading.ac.uk/centaur }}$}

\section{CentAUR}

Central Archive at the University of Reading

Reading's research outputs online 
This is an electronic version of an article published Hall, N.R. \& Crisp, R.J. (2010). Selfactivation and outgroup contrast. The Jurnal of Social Psychology, 150 (5), 423-427. The journal of Social Psycholoy is available online at:

http://www.informaworld.com/smpp/content $\sim \mathrm{db}=$ all $\sim$ content=a926889170 frm=titlelink

Self-activation and outgroup contrast

Natalie R. Hall

University of Reading

Richard J. Crisp

University of Kent

Word count: 996

Author note

Correspondence concerning this article should be addressed to N. R. Hall, School of Psychology and Clinical Language Sciences, University of Reading, Earley Gate, Whiteknights Road, Berkshire, RG6 6AL, Email: Natalie.Hall@reading.ac.uk or R. J. Crisp, Centre for the Study of Group Processes, Department of Psychology, Keynes College, University of Kent, Canterbury, Kent, CT2 7NP, UK. 
Stereotype priming has been shown to influence social perceivers' subsequent automatic behavior (Bargh, Chen, \& Burrows, 1996). When group memberships are salient an ingroup stereotype prime (e.g., female) leads to assimilative behavior, (e.g., poor math performance) and an outgroup stereotype prime (male) leads to contrastive behavior, (e.g., excellent math performance; Gordijn \& Stapel, 2006; Spears et al., 2004). The mechanism by which outgroup primes lead to contrastive responding has been the subject of some debate.

Contrastive responding to an outgroup has been shown to be associated with the activation of the ingroup (Gawronski, Bodenhausen, \& Banse, 2005; Mussweiler \& Bodenhausen, 2003), particularly when the intergroup context is salient to the social perceiver (Schubert \& Häfner, 2003; Spears et al., 2004; Gordijn \& Stapel, 2006). Hall and Crisp (2008) suggested that the intergroup context will be spontaneously salient for those perceivers who highly identify with their ingroup and so these perceivers should be more likely to differentiate (contrast) their group from an outgroup prime. This hypothesis was supported by Hall and Crisp: Following an outgroup (male) prime, higher identifying female participants contrasted from the outgroup (male) stereotype by confirming the ingroup (female) stereotype (performing poorly on a math test). The authors suggested that higher identifiers are automatically activating the ingroup and self-stereotyping when they encounter an outgroup.

The research reviewed above highlights the role of ingroup activation in predicting outgroup contrast. Other research rooted in interpersonal contexts has suggested that personal-self activation predicts differentiation and contrastive responding. For example, Stapel \& Koomen (2001) demonstrated that a broad activation of the personal-self is analogous to priming a differentiation mindset and can lead to contrastive responding. Herein we attempt to reconcile these two perspectives by providing initial evidence that contrastive responding in intergroup contexts could operate by priming both the intergroup and the personal-self. We argue that outgroup contrast for 
higher identifiers is caused by the co-activation of both the ingroup and the personal-self. The representation of personal-self and the ingroup (social) self are overlapping and this overlap is greater for higher identifiers (Smith \& Henry, 1996). Therefore we propose that outgroup-primed higher identifiers will simultaneously and spontaneously activate both the ingroup and the personalself (because they are overlapping) as a means of differentiating themselves from the outgroup. Given that research reviewed above has highlighted the role of ingroup activation, here we focus on investigating personal-self activation within the same paradigm as Hall and Crisp (2008).

Method

\section{Participants and design}

Thirty-six female participants (mean age 19.5 years) were randomly allocated to the ingroup (female) or outgroup (male) stereotype priming condition using a between-participants design with ingroup-identification treated as a continuous independent variable.

\section{Procedure}

Participants were told they would complete several unrelated pre-tests. Participants were asked to rate their agreement with four-items that measured identification with the group female (adapted from Branscombe, Wann, Noel, \& Coleman, 1993; Luhtahnen \& Crocker, 1992) from 1 (not at all) to 9 (very much). Examples items are "I identify strongly with other females", and "I feel a sense of solidarity with other females". The four-item scale has been used previously (Hall \& Crisp, 2008) and was reliable with Cronbach's alpha $=.84$. Stereotypes were then primed by asking participants to spend five minutes thinking about the typical attributes, lifestyle, and behaviors of either the ingroup (female) stereotype or the outgroup (male) stereotype (Dijksterhuis et al., 1998). On completion of the priming task participants ostensibly completed a lexical-decision task; this was the measure of personal-self activation. Drawing on the work of Dijksterhuis et al., who primed the personal-self using personal-self pronouns, we measured the activation of the personal-self 
using similar personal-self descriptors. Participants completed a lexical-decision task which consisted of 20 practice trials and 60 test trials. The test trials consisted of 15 personal self words (me, my, mine, repeated five times), 15 controls words matched for length and frequency (up, an, send, repeated five times), and 30 pronounceable non-words. Following a fixation of two seconds, participants responded to whether the stimulus was a word or a non-word on the keyboard.

\section{Results and Discussion}

Each participant's mean reaction-time to personal-self words was calculated after removing all errors and outliers (mean $\pm 2 \mathrm{SD}$ ). The reaction-time data met assumptions of normality and homoscedascity. A moderated regression analysis on self-words revealed no main effect of priming condition, $\beta=-.190, t=-1.38, p=.18$, and a significant main effect of ingroup identification, $\beta=-$ $.677, t=-4.81, p<.01$ (higher identifiers respond more quickly to self-words). The ingroup identification effect was qualified by a significant interaction, $\beta=-.276, t=-2.01, p=.05$. Post-hoc regression analyses were computed at lower and higher identification points defined as the mean (26.7) of the continuous identification score \pm 1SD (4.41) (Aiken \& West, 1991). These analyses revealed that at the lower identification point reaction-times to self-words between the ingroup and outgroup priming condition did not differ $\beta=0.08, t=0.43, p=.67$. At the higher identification point there was a significant difference in reaction times to self-words between the ingroup and outgroup priming condition $\beta=-0.49, t=-2.34, p=.026$, higher identifiers responded quicker to self words following an outgroup prime than following an ingroup prime suggesting that higher identifiers primed with the outgroup showed increased activation of the personal self.

The personal self was facilitated under conditions known to produce contrastive responding. Outgroup-primed higher identifiers showed greater personal-self activation suggesting that personal-self activation may contribute to their contrastive behavioral responses. This study 
provides initial evidence that personal-self activation may explain contrastive responding in an intergroup context. We propose that the activation of the personal-self occurs alongside activation of the ingroup, and that it is the co-activation of these facets of the self that drive contrastive responding to outgroup stereotypes (particularly for higher identifiers). Further research should directly compare personal-self (me, my mine) and social-self (e.g., we, our, ours, Brewer \& Gardner, 1996) activation following the activation of an outgroup stereotype. 


\section{References}

Aiken, L. S., \& West, S. G. (1991). Multiple Regression: Testing and interpreting interactions. Newbury Park, CA: Sage.

Bargh, J. A., Chen, M., \& Burrows, L. (1996). Automaticity of social behavior: Direct effects of trait construct and stereotype activation on action. Journal of Personality and Social Psychology, 71(2), 230-244.

Branscombe, N. R., Wann, D. L., Noel, J. G., \& Coleman, J. (1993). In-group or out-group extremity: Importance of the threatened social identity. Personality and Social Psychology Bulletin, 19, 381-388.

Brewer, M. B., \& Gardner, W. L. (1996). Who is this "we"? Levels of collective identity and self representations. Journal of Personality and Social Psychology, 71, 83-93.

Dijksterhuis, A., Spears, R., Postmes, T., Stapel, D., Koomen, W., van Knippenberg, A., et al. (1998). Seeing one thing and doing another: Contrast effects in automatic behavior. Journal of Personality and Social Psychology, 75 (4), 862-871.

Gawronski, B., Bodenhausen, G. V., \& Banse, R. (2005). We are therefore they aren't: Ingroup construal as a standard of comparison for outgroup judgments. Journal of Experimental Social Psychology, 41(5), 515-526.

Gordjin, E. H., \& Stapel, D. A. (2006). Behavioural effects of automatic interpersonal versus intergroup comparison. British Journal of Social Psychology, 42, 717-729.

Hall, N. R., \& Crisp, R. J. (2008). Assimilation and contrast to group primes: The moderating role of ingroup identification. Journal of Experimental Social Psychology, 44 (2), 344-353.

Luhtanen, R., \& Crocker, J. (1992). A collective self-esteem scale: Self-evaluation of one's social identity. Personality and Social Psychology Bulletin, 18(3), 302-318. 
Mussweiler, T., \& Bodenhausen, G. V. (2002). I know you are, but what am I? Self evaluative consequences of judging the in-group and out-group members. Journal of Personality and Social Psychology, 82 (1), 19-32.

Smith, E. R., \& Henry, S. (1996). An ingroup becomes part of the self: Response time evidence. Personality and Social Psychology Bulletin, 22(6), 635-642.

Spears, R., Gordjin, E., Dijksterhuis, A., \& Stapel, D. A. (2004). Reaction in action: Intergroup contrast in automatic behavior. Personality and Social Psychology Bulletin, 30 (5), 605-616.

Stapel, D. A., \& Koomen, W. (2001). I, we and the effects of others on me: How self-construal level moderates social comparison effects. Journal of Personality and Social Psychology, 80 (5), 766-781. 